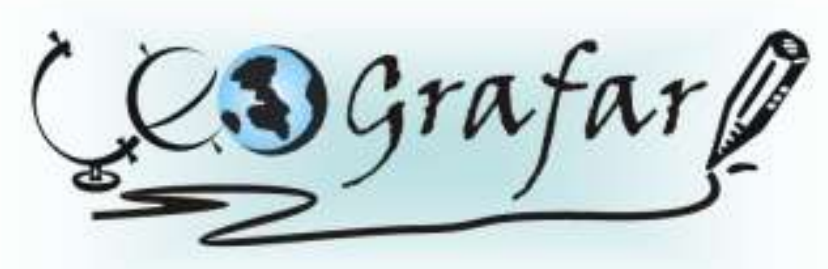

Revista Eletrônica do Programa de Pós-Graduaçāo em Geografla - UFPR

\title{
SÃO LUIZ DO PARAITINGA-SP: UM ESPAÇO CONCEBIDO/APROPRIADO COMO LUGAR DA VIDA ${ }^{1}$
}

\author{
DANILO CELSO PEREIRA ${ }^{2}$
}

\begin{abstract}
RESUMO
Esse artigo pretende abordar questões referentes a uma nova abordagem teóricometodológica sobre o tema do patrimônio cultural no âmbito da ciência geográfica. $\mathrm{Na}$ atualidade as discussões acerca do patrimônio cultural estão cada vez mais centradas nas questões da identidade e é na escala do lugar que ela se estabelece, sendo esta uma categoria concreta de análise do espaço geográfico. É no lugar que se guarda o significado e as dimensões do movimento da história, passível de ser apreendida pela memória decorrente da acumulação dos tempos, natureza transformada pela prática social, acumulando cultura que se insere em um espaço e tempo. Elegemos como estudo de caso o conjunto urbano de São Luiz do Paraitinga (SP), destacando as características do seu espaço concebido que nos remetem ao urbanismo ilustrado português que fizeram deste conjunto um exemplar paradigmático no sul e no sudeste do Brasil, o que justificou o seu reconhecimento como Patrimônio Cultural Nacional pelo IPHAN em 2010, ressaltando que o mesmo é acautelado pelo CONDEPHAAT desde 1982, sendo o seu maior conjunto urbano tombado. Procuramos entender como este espaço concebido é apropriado pela população local como espaço vivido, lugar de ver e ser visto e das mais diversas manifestações culturais, o patrimônio imaterial.
\end{abstract}

Palavras-chave: patrimônio cultural, identidade, lugar, espaço concebido e vivido, São Luiz do Paraitinga.

\footnotetext{
${ }^{1}$ Este artigo é resultado do Trabalho de Graduação Individual "O patrimônio ambiental urbano de São Luiz do Paraitinga e as políticas públicas de preservação" apresentado ao Departamento de Geografia da Faculdade de Filosofia, Letras e Ciências Humanas da Universidade de São Paulo em 2012.

${ }^{2}$ Geógrafo pela Universidade de São Paulo, membro do Grupo de Pesquisa do CNPq Planejamento e Monitoramento de Áreas Naturais Protegidas (Instituto Florestal do Estado de São Paulo) na linha de pesquisa "Conservação da natureza e diversidade sociocultural”; e-mail: dcpgeo@hotmail.com
} 


\title{
SÃO LUIZ DO PARAITINGA-SP: A CONCEIVED SPACE / APPROPRIATE AS A PLACE OF LIFE
}

\begin{abstract}
This article intends to address issues relating to a new theoretical and methodological approach on the issue of cultural heritage within the geographical science. The current discussions about cultural heritage are increasingly focused on questions of identity and they are established in the scale of the place, this category being a particular type of analysis of geographical space. It is the place that holds the meaning and dimensions of history's movements, which can be grasped by the memory arising out of the accumulation of time, by the nature transformed through social practice, thereby accumulating the culture which is inserted at a certain space and time. We chose as a case study the urban area of São Luiz do Paraitinga-SP, highlighting the features of its conceived space related to the Portuguese illustrated urbanization which have made this area a paradigmatic example in southern and southeastern Brazil. This justifies its recognition as a National Cultural Heritage by IPHAN in 2010, stressing that it is safeguarded by CONDEPHAAT since 1982, its greater urban center registered as a historic site. We intend to understand how this conceived space is appropriate by local people as living space, a place to see and to be seen and of many different cultural events, its intangible heritage.
\end{abstract}

Keywords: Cultural Heritage. Identity. Place. Conceived and Living Space

\section{INTRODUÇÃO}

Com a globalização as grandes cidades passaram a desempenhar um papel de protagonismo nos processos sociais, econômicos e políticos de fato, além do cultural no imaginário das pessoas. Acredita-se que são apenas esses aglomerados urbanos, sobretudo as metrópoles, que nos possibilitam uma vida culturalmente intensa, pois são nesses espaços que se tem acesso aos grandes espetáculos que circulam as grandes cidades do mundo todo, é onde se pode contemplar edifícios projetados pelos mais renomados arquitetos internacionais, porém, são esses bens culturais que nos representam? É essa cultura massificada que nos confere identidade?

Essa identidade é construída por pequenas coisas do cotidiano, por expressões culturais que, apesar de não serem hegemônicas, deixaram registradas na paisagem elementos de diferentes temporalidades, e através de uma analise 
mais apurada sobre esses elementos podemos entender como o espaço geográfico foi produzido.

Esses elementos também estão presentes nas grandes cidades, mas são nas pequenas cidades de assentamento mais antigo e que permanecem mais ligadas às práticas tradicionais, em especial os costumes religiosos, que notamos uma maior valorização dos elementos que na atualidade denominamos de patrimônio cultural. Isso se deve, segundo Francisco (2008), não apenas pela sobrevivência dos bairros rurais e sua interação com as cidades no interior, mas é resultado da permanência de uma cultura citadina eminentemente caipira ${ }^{3}$, onde a identidade tradicional é mais forte.

Esses elementos que nos conferem identidade são tutelados pelo Estado, ficando a cargo deste garantir a sua salvaguarda através dos seus órgãos de preservação do patrimônio cultural, na esfera federal pelo Instituto do Patrimônio Histórico e Artístico Nacional (IPHAN) e na do estado de São Paulo pelo Conselho de Defesa do Patrimônio Histórico, Artístico, Arqueológico e Turístico (CONDEPHAAT).

Porém, esses órgãos em muitos momentos buscaram forjar uma identidade que representassem toda a população, seja uma identidade nacional, no caso do IPHAN, ou paulista, no caso do CONDEPHAAT. Contudo, segundo Carlos (1996), a identidade só se estabelece com o lugar, são nesses espaços que a vida cotidiana acontece, na escala do espaço vivido como aquela onde se dão a reprodução da vida e as relações sociais que fundam um vínculo entre os lugares e os objetos materiais.

Dentre esses objetos materiais temos as edificações que foram o principal foco das políticas de preservação do patrimônio cultural no Brasil. A busca em forjar uma suposta identidade nacional fez com que se buscassem nos estados de Minas Gerais, Bahia e Rio de Janeiros os bens que identificavam a cultura nacional, em detrimento de outros estados como São Paulo, que possui em seu território cidades antigas, fundadas no auge do açúcar e do café, ou ainda mais antigas que se

\footnotetext{
${ }^{3}$ Do mesmo modo que em Antonio Candido (1987), caipira aqui é entendido como o homem que surgir da miscigenação do índio e do europeu, com estilo de vida simples e forte ligação com a terra. Nesse sentido, incluímos os caiçaras a esse grupo, admitindo que a sua relação com o mar lhe traz especificidades.
} 
remetem ao tropeirismo e que guardam testemunhos tão significativos quanto os estados privilegiados.

Dentre esses municípios antigos fundados durante o tropeirismo destaca-se São Luiz do Paraitinga. Para Marins (apud Bocchini, 2010), esse município somente encontra paralelos em localidades como Pirenópolis (GO) ou Olinda (PE) no que diz respeito à clara convergência entre o patrimônio material e imaterial, configurandose este como uma verdadeira relíquia paulista.

Além disso, o autor ainda destaca que a maioria das cidades paulistas antigas possui grandes sobrados neoclássicos, porém, nenhuma no Estado com um conjunto do século XIX tão significativo como em São Luiz do Paraitinga, o que torna esse lugar privilegiado para o estudo patrimonial em São Paulo. Sendo assim, este trabalho pretende abordar, de um ponto de vista geográfico, no que se constitui o patrimônio cultural de São Luiz do Paraitinga, as relações entre o espaço concebido e o vivido (Lefebvre, 1974), ou seja, as normativas impostas a esse núcleo urbano e as formas de apropriação dessas pela população local, levando-se em conta a ordem distante e a ordem próxima (Lefebvre, 1991) na organização do espaço geográfico dessa cidade, ou seja, o papel do estado na concepção desse espaço e como a população se apropria deste como lugar (Carlos, 1996) da vida.

$\mathrm{Na}$ atualidade a discussão desse tema torna-se relevante socialmente, uma vez que as políticas de proteção do patrimônio no Brasil estão cada vez mais ligadas às práticas sociais e às memórias coletivas. Para Scifoni (2006), a identificação dos valores do bem a ser preservado leva em conta as relações dos grupos com o lugar, as práticas socioespaciais. Essa autora salienta ainda que é na escala do local que os conflitos da esfera do patrimônio se afloram, na medida que eles expõem a luta entre a busca da apropriação social do espaço geográfico, a intervenção ordenadora do Estado e os interesses do capital, configurando-se assim o universo da cultura como um campo de lutas, conflitos e tensões políticas.

No contexto da ciência geográfica questões referentes ao patrimônio se justificam, pois, segundo Milton Santos (1997), os testemunhos do passado, resultantes da acumulação desigual dos tempos ficam marcados na paisagem, revelando um dinamismo evolutivo através dos tempos (diacrônico), resultante do processo espacial. Os objetos são expressos pelas formas que, embora fixas, se 
reportam aos diferentes extratos sociais. A forma é o aspecto visível, refere-se a uma maneira ordenada de organização do presente e, mesmo tentando ignorar seu passado, este continua descrito em suas formas.

\section{PATRIMÔNIO CULTURAL: UMA PROPOSTA DE ABORDAGEM TEÓRICO- METODOLÓGICA GEOGRÁFICA}

Questões referentes ao patrimônio cultural vêm articulando alguns saberes acadêmicos, tateando entre a Arquitetura, o Urbanismo, a História e a Antropologia, estas já consagradas. Porém, é importante salientar a importante contribuição que a Geografia pode conferir a esse tema, sendo esta a ciência detentora de conceitos e metodologias que propiciam a investigação do espaço geográfico, visto que as experiências sociais não se fazem fora do espaço, o homem ao ocupar e agir sobre a natureza produz o espaço e deixa registrado nele a sua história.

Porém, espaço geográfico não é algo assim tão fácil de conceituar devido às discordâncias teóricas a esse respeito. Dessa maneira, já iniciamos esta discussão com um grande desafio: escolher uma linha teórico-metodológica de espaço geográfico que norteará todo esse artigo.

Em Carlos (1996), o espaço geográfico é social, produto do processo de trabalho geral da sociedade em cada momento histórico. Assim, as parcelas do espaço socialmente e historicamente produzidas se apresentam enquanto trabalho materializado e acumulado a partir de sucessivas gerações e, nesse caso específico, o espaço como um todo tem valor e se reproduz a partir de seus usos sempre diferenciados, condizentes com as singularidades de cada lugar. A autora ressalta que o processo de produzir/reproduzir é também um ato de apropriação, nesse contexto o sentido do espaço produzido é aquele marcado por modos de produção e, consequentemente, de apropriação.

Também em Lefebvre (1976), o espaço é empreendido como produção da sociedade, fruto da reprodução das relações em sua totalidade. Para esse autor, o espaço é socialmente produzido, apropriado e transformado.

Dentro dessa análise de espaço social, Lefebvre (1974) propõe uma dupla perspectiva de apreciação do espaço: o espaço concebido e o espaço vivido. 0 
espaço concebido corresponde aos discursos e as práticas de como conceber e representar o espaço, ou seja, toda a normativa que interfere no processo de produção do espaço urbano. Para Lefebvre (1974), são os fatores ideológicos que orientam as ações humanas, estão ligados aos modos de produção, à ordem para lá dos conhecimentos, dos signos, dos códigos.

O espaço concebido em São Luiz do Paraitinga corresponde às normativas rígidas estabelecidas pelo urbanismo ilustrado quando da sua fundação, assim como às impostas pelos órgãos de preservação do patrimônio cultural na atualidade.

O espaço vivido corresponde às imagens, sensações, opiniões, aos símbolos e signos criados com a vivência do lugar. Para Lefebvre (1974), o espaço vivido apresenta os símbolos complexos, ligando-se ao lado clandestino e subterrâneo da vida, mas também à arte, que se corrompe eventualmente e é definida não como um código espacial, mas como um código dos espaços de representação.

O espaço vivido possui importante relevância neste estudo, pois nos permite analisar uma das principais peculiaridades do espaço em São Luiz do Paraitinga: um espaço intensamente vivido pela população local, lugar das mais diversas manifestações culturais, espaço de ver e ser visto.

O espaço é constantemente concebido e vivido pelos homens em virtude dos seus sistemas de pensamento e de suas necessidades. Dessa maneira, essas categorias se mostram extremamente relevantes para se analisar o espaço geográfico, um contínuo resultado das relações socioespaciais, relações estas que são econômicas, políticas e simbólico-culturais. Como ressalta Lefebvre (1991), a força motriz destas relações são sempre as ações humanas e suas práticas espaciais.

Ao discutir os fenômenos do urbano, Lefebvre (1991) lança mão de uma dialética que é muito cara a este texto: a relação entre a "ordem próxima" e a "ordem distante". Aqui, o autor irá afirmar que a cidade passará a mudar quando a sociedade mudar, ressaltando que não se trata de uma mudança apenas em escala global, mas ressaltando a escala do local, onde a ordem próxima corresponderia aos habitantes dessa cidade, os responsáveis por constituí-la em espaço vivido, e pela ordem distante representada pelas instituições, como o Estado e a Igreja, ou seja, os responsáveis pelo espaço concebido. $\mathrm{O}$ autor destaca que esta ordem distante se 
institui num nível superior, dotada de poderes, e se impõe ao nível próximo, ela impõe sua lógica, sua racionalidade sobre as práticas sociais no espaço vivido.

$\mathrm{Na}$ atualidade as discussões acerca do patrimônio cultural estão cada vez mais centradas nas questões da identidade e é na escala do lugar que ela se estabelece, sendo esta outra categoria de análise da geografia. Esse conceito expressa de maneira clara e objetiva a posição adotada para se interpretar o empírico deste trabalho. Para Carlos (1996), é no lugar que se desenvolve a vida em todas as suas dimensões, a prática do cotidiano, o espaço vivido e a dialética da "ordem distante" e a "ordem próxima" de Lefebvre (1991).

É o conceito do lugar que permite analisar o espaço como resultante de uma história particular que se realiza, segundo Carlos (1996), em função da cultura/tradição/língua/hábitos que lhes são próprios. $\mathrm{Na}$ cidade produz-se e reproduz-se o plano da vida e do indivíduo, e a relação que este mantém com os espaços habitados se exprime diariamente como se usa, sente, pensa, apropria e vive o lugar através do corpo.

Para Carlos (1996), o lugar é a porção do espaço apropriado para a vida através dos passos de seus moradores pelas ruas e praças e, nesse sentido, ressalta a autora, não seria nunca na metrópole que essa relação se daria, mas sim nas pequenas vilas ou cidades vividas/conhecidas/reconhecidas em todos os cantos.

Sendo assim, podemos concluir que a produção do espaço se dá no plano do cotidiano e aparece nas formas de apropriação de um determinado lugar, num momento específico, revelando-se pelo uso como produto da divisão social e técnica do trabalho que produz uma morfologia espacial fragmentada e hierarquizada (CARLOS, 1996).

Quanto a identidade, é no lugar que se guarda o significado e as dimensões do movimento da história, passível de ser apreendida pela memória decorrente da acumulação dos tempos, marcados, remarcados e nomeados. Natureza transformada pela pratica social, acumulando cultura que se insere em um espaço e tempo (CARLOS, 1996).

Porém, ao discorrer sobre o lugar, não podemos ignorar a relação deste com o mundial. Carlos (1996) salienta que o lugar se produz na articulação contraditória 
entre o mundial que se anuncia e as especificidades do lugar, então este se apresenta como o ponto de articulação entre a mundialidade em constituição e o local enquanto especificidade concreta. É nessa articulação que a ordem próxima não deveria se anular com a enunciação do mundial, pois, nesse caso, o lugar abre perspectiva para pensar o viver e o habitar, o uso e o consumo, a apropriação do espaço.

Sendo assim, entendendo o espaço vivido de São Luiz do Paraitinga enquanto lugar com o qual a população local, a ordem próxima, estabelece identidade e, ao mesmo tempo, este é reconhecido como centro histórico pelos órgãos de preservação, a ordem distante, podemos concluir que a identidade se estabelece com os bens reconhecidos pelo Estado como patrimônio cultural.

\section{SÃO LUIZ DO PARAITINGA: UMA RELÍQUIA PATRIMONIAL PAULISTA}

Agora pretendemos discutir as relações entre o espaço concebido e o vivido (Lefebvre, 1974), ou seja, as normativas impostas a São Luiz do Paraitinga e as formas de apropriação dessas pela população local, levando-se em conta a ordem distante e a ordem próxima (Lefebvre, 1991) na organização do espaço geográfico dessa cidade, ou seja, o papel do Estado na concepção desse espaço e como a população se apropria deste como lugar (Carlos, 1996) da vida.

Cidade iluminista ou urbanismo ilustrado são maneiras de se referir aos núcleos urbanos fundados em todo o Brasil e em Portugal durante o governo do Marquês de Pombal, núcleos submetidos a um plano previamente desenhado. Nesse sentido, uma fundação só pode ser vinculada ao urbanismo ilustrado se estiver situada no contexto do urbanismo pombalino, assim como ao tradicional urbanismo português. O conceito de "cidade iluminista" é utilizado desde 1982 pelo historiador português José Eduardo Horta Correia em relação à Vila Real de Santo Antônio, planejada e construída por ordem do Marquês de Pombal, contemporânea à São Luiz do Paraitinga (IPHAN, 2010).

Desde a Grécia que a ideia física de cidade comporta dois aspectos de que, até hoje, somos herdeiros: cidade como o lugar da ordem social e política, é o espaço vivido, além de se constituir como lugar da representação e do exercício do 
poder. Já o outro aspecto se reporta a cidade como polo hierárquico da organização do território, centro a partir de onde se estabelece o controle do território.

As cidades de origem portuguesa têm características morfológicas específicas, para Teixeira (1999), essas características a diferenciam das cidades de outras culturas. Dentre esses aspectos, destaca-se o seu desenvolvimento através de sucessivos processos de adaptação e de síntese, ressaltando a escolha da localidade, das formas, das lógicas de localização dos principais edifícios, no traçado das vias estruturantes, na localização das praças e o seu papel na organização do espaço urbano.

Portugal, ao entrar no Século das Luzes, se beneficia de uma vasta tradição urbanística, o que ficou explícito durante a profunda reforma urbana da cidade de Lisboa, após o terremoto de 1755 , que previa a articulação entre duas praças remanescentes e a praça que passaria a abrigar o Paço e o Rossio, além de atribuir à arquitetura uma função de normatização urbana (CORREIA, 1985).

A arquitetura e o urbanismo pombalino foram marcados por valores como a uniformidade, a ordem, a sobriedade e padronização, totalmente inserida numa conjuntura ideológica filiada ao iluminismo reformador, que procurava o fortalecimento do poder do rei através da intervenção em vários setores da vida, entre eles da vida urbana (CORREIA, 1985).

Vila Real de Santo Antonio é um expoente representante de espaço concebido pelo urbanismo ilustrado em Portugal. A vila surge às margens do Rio Guadiana, que marca a fronteira com a Espanha. Correia (1985) salienta que esta foi fundada sobre um rígido plano geométrico que utiliza os mesmos parâmetros formais na totalidade da vila, onde os conhecimentos gerados na experiência de Lisboa são aplicados de forma racional, com o objetivo de reafirmar o poder do Estado português face ao Estado espanhol. Por isso, este se constitui um exemplo de cidade perfeita do lluminismo, pois a sua construção é fundamentada pela necessidade de reafirmação do poder real que se pretende "iluminista" e "perfeito". 
FIGURA 1 - PLANTAS PRÉVIAS: 1 - BRAGANÇA NO PARÁ (1753); 2 - PORTO COVO EM PORTUGAL (1794); 3 - SÃO LUIZ DO PARAITINGA EM SÃO PAULO (1759)
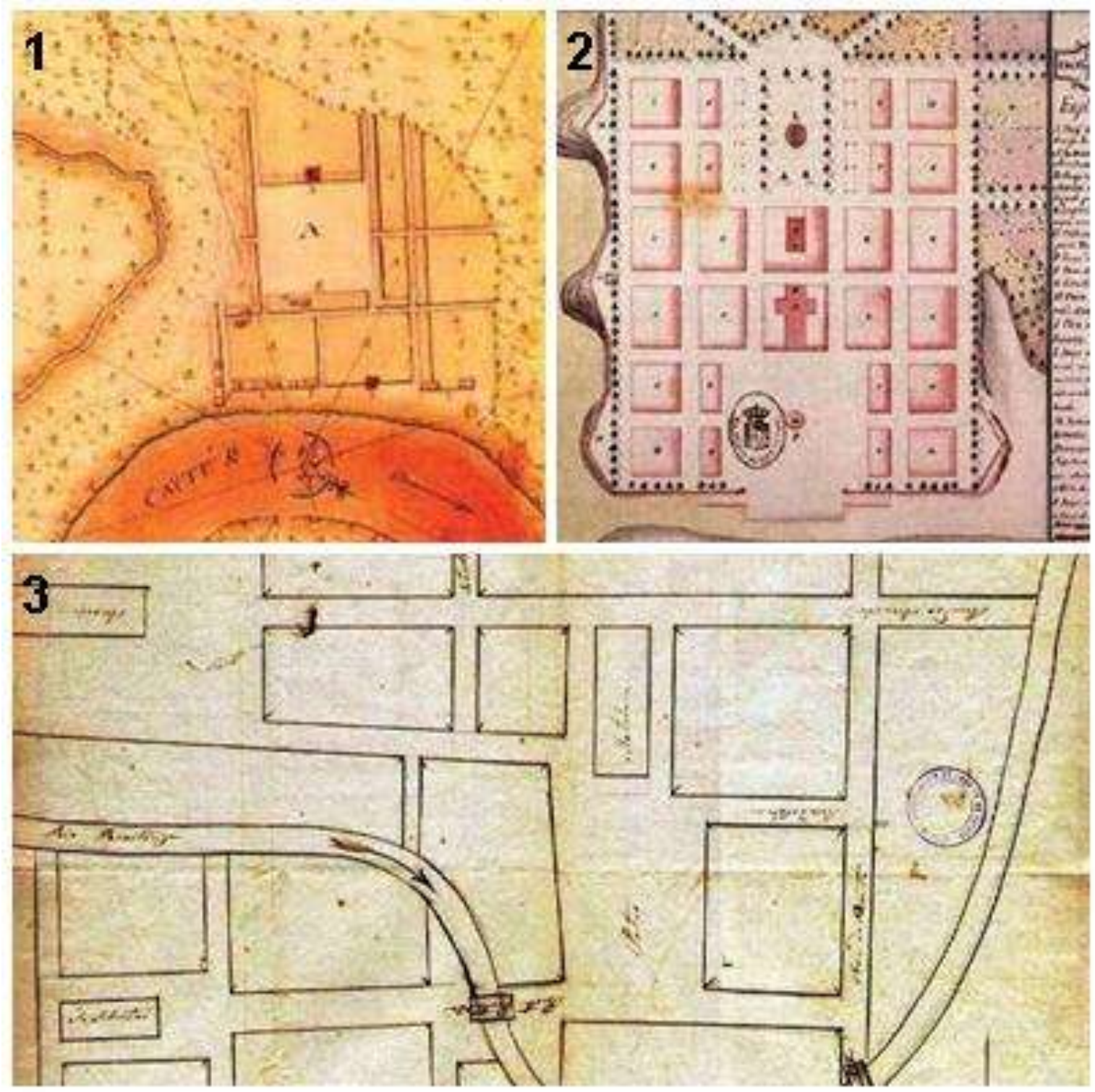

Fonte: IPHAN (2010), organizado por Danilo Pereira. 
Nesse contexto, no que se refere ao Brasil, tivemos a fundação de núcleos organizados que passavam a consolidar a presença do Estado e o povoamento de regiões no norte e o nordeste, em particular no Grão-Pará e no Maranhão entre 1751 e 1759, quando os administradores coloniais passam a governar sob um prisma da razão política, impondo sua autoridade em nome de um "bem-estar da sociedade" a ser alcançado pela instrução e civilização (IPHAN, 2010).

Os responsáveis pela administração das vastas províncias da América portuguesa, onde se instalavam grandes tensões com a Espanha relativas ao estabelecimento das fronteiras, fez com que, no sul do Brasil, se elegesse São Paulo como a única capitania com capacidade efetiva de apoiar as ações da Coroa portuguesa. Nesse sentido, o Governador e Capitão-General da Capitania de São Paulo, D. Luís Antônio Mourão, o Morgado de Mateus, passa a criar novos núcleos de povoação para consolidar e incrementar a trama de caminhos que garantia a circulação mercantil e de tropas militares, além de possibilitar a ocupação do território.

Em São Paulo, diferentemente do ocorrido em outras partes do Brasil, as fundações surgiram articuladas a um plano territorial cujas orientações possuíam um claro víeis fisiocrático, visando o controle da população e o domínio do território (IPHAN, 2010).

São Luiz do Paraitinga, criado nesse contexto histórico, acabou florescendo. A ligação da região entre São Paulo, Rio de Janeiro, Minas Gerais e o litoral, concentrado no porto de Paraty o principal destino nas manufaturas, portanto sob jurisdição do Rio de Janeiro, foi aos poucos derivando para o porto de Ubatuba, tornando a passagem por São Luiz praticamente obrigatória.

A construção de núcleos urbanos "regulares" resulta de uma estratégia política e territorial de afirmação do poder do Estado, ou seja, uma imposição da ordem distante sobre a ordem próxima (Lefebvre, 1991). O local escolhido, uma várzea do Rio Paraitinga entre os morros da Serra do Mar, reunia as condições ideais para a fundação do povoamento, porém, com o crescimento desse aglomerado, a várzea se torna pequena e o traçado urbano regular é obrigado a se adaptar ao relevo acidentado do entorno da várzea do rio. 
Os elementos estruturantes da malha urbana de São Luiz do Paraitinga tiveram o Rio Paraitinga como principal eixo de organização e remontam da fundação do núcleo, 1773. Estes compõem um plano traçado em forma de tabuleiro, com regularidade geométrica, porém, é importante ressaltar que essa concepção de espaço não se restringiu apenas aos planos, mas também aos imóveis, que deveriam seguir os princípios da uniformidade e regularidade para se obter a harmonia do conjunto. Como ressalta o IPHAN (2010), se buscava a "formosura" da vila.

Nessa conjuntura de normatização urbana, destaca-se a Praça da Matriz como grande eixo viário principal, um retângulo que se estende desde as margens do rio até o sopé do morro, dando origem a outras quadras paralelas a ela (Figura 2). É importante ressaltar que essas quadras foram demarcadas com mourões mesmo antes de sua ocupação, o que reforça o caráter planejado do presente núcleo urbano.

Nesse traçado geométrico e antigo restam numerosos exemplares da arquitetura tradicional, construídos em taipa de pilão e pau a pique ${ }^{4}$. Dentre estes, se destacam dois conjuntos pela homogeneidade arquitetônica e por serem os principais remanescentes dos princípios da regularidade, simetria e uniformidade que se impuseram pela ordem distante desde a fundação desse núcleo. O primeiro é a Rua do Carvalho, com suas pequenas casas de "meia" e "morada inteira" destinadas à população mais pobre. É importante ressaltar que esse conjunto de casas se alinha a lateral da Igreja do Rosário dos Homens Pretos (Figura 3), santa cultuada pelos escravos. O segundo é a Praça da Matriz (Praça Dr. Oswaldo Cruz), com suas construções em sobrados, com fachadas corridas, onde se instalou a elite local (Figura 4).

\footnotetext{
${ }^{4}$ Talvez nesse momento seja relevante descrever sucintamente as duas principais técnicas que dominaram as construções paulistas até o século XIX, a taipa de pilão e o pau a pique. A primeira constituía em socar terra com pilão de madeira em grandes formas retangulares chamadas taipais, e, após a secagem da primeira camada se sobrepunha a ela a mesma forma para a execução da próxima camada colada a primeira e assim sucessivamente até se completar a parede. Essa técnica construtiva, uma marca registrada dos paulistas, também pode ser verificada em outras localidades como em Minas Gerais, Goiás, Mato Grosso e Paraná, e isso se deve a dispersão decorrente do bandeirismo e do tropeirismo. Já o pau a pique se constitui em um entrecruzamento de paus amarrados ou presos a uma estrutura mais firme que servia de alicerce, e este era preenchido com barro que, posteriormente era alisado com a mão. Essa técnica, mais frágil em comparação a taipa de pilão, foi a mais usada nas construções populares.
} 


\section{FIGURA 2 - IMAGEM ÁREA DO CENTRO HISTÓRICO DE SÃO LUIZ DO} PARAITINGA, EM 2009.

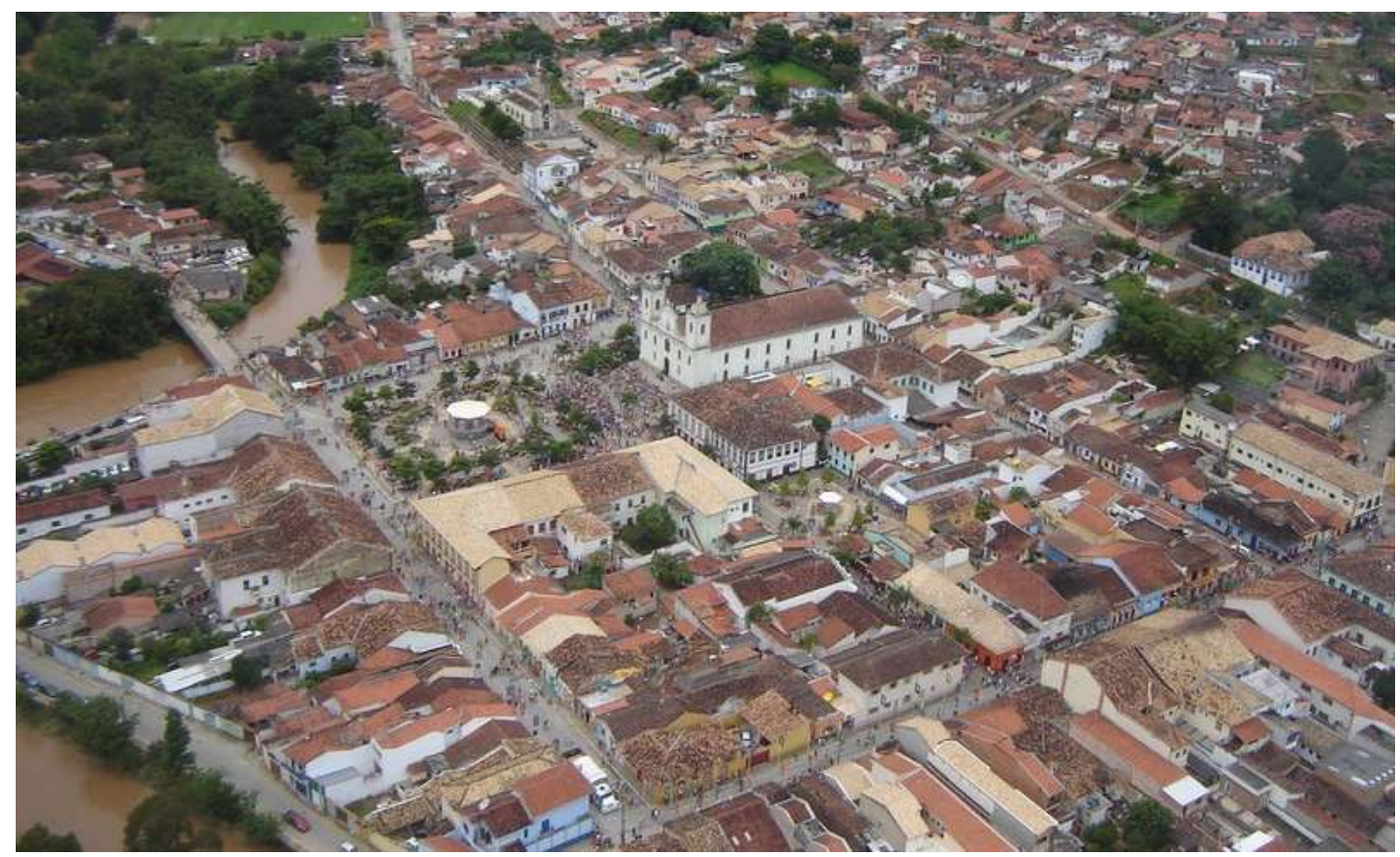

Fonte: PMSLP.

FIGURA 3 - IGREJA DO ROSÁRIO DOS HOMENS PRETOS E A RUA DO CARVALHO, EM 2009.

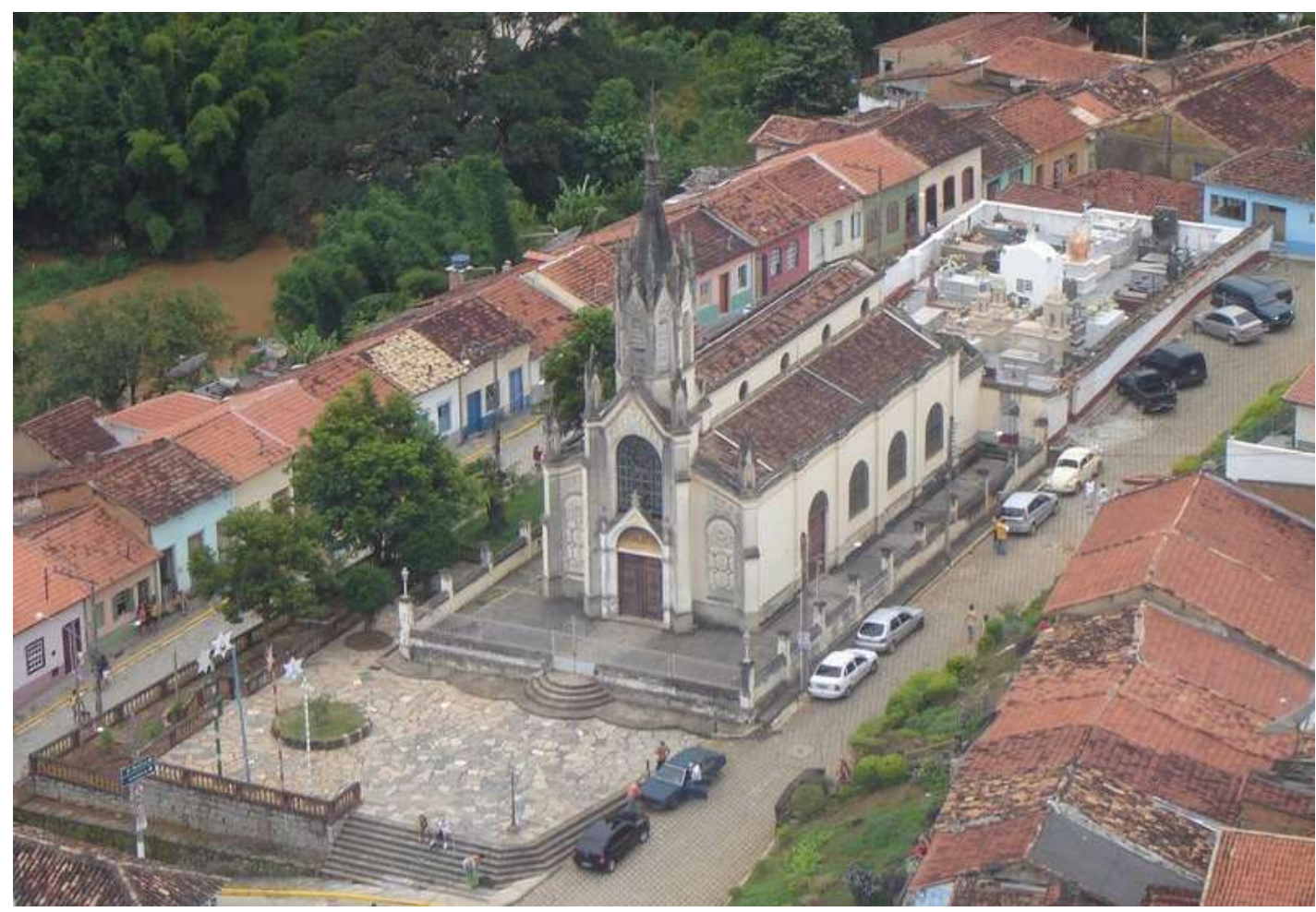

Fonte: PMSLP. 
Datadas de 1830 e 1840, as pequenas moradias da Rua do Carvalho são notáveis pela sua extensão, homogeneidade e antiguidade. É o mais extenso conjunto de casas térreas de feição tradicional existentes no estado de São Paulo (IPHAN, 2010).

Assim como na praça central, houve nessa rua a preocupação em se manter as cumeeiras no mesmo nível, buscando regularidade e simetria, com fachadas térreas corridas, predominando ora as moradias de um lanço, de porta e janela, ora as de dois lanços, com três vãos na fachada, porta e duas janelas (IPHAN, 2010).

Mesmo com o intuito de privar essa população mais pobre de residir na área mais valorizada da cidade (a praça), não foi possível privá-la de vivenciar esse espaço, devido às dimensões desse núcleo urbano. Sendo assim, a Praça da Matriz, desde a época de sua fundação, até os dias de hoje, se constitui com um espaço da vida por excelência.

FIGURA 4 - PRAÇA DR. OSWALDO CRUZ, EM 2009

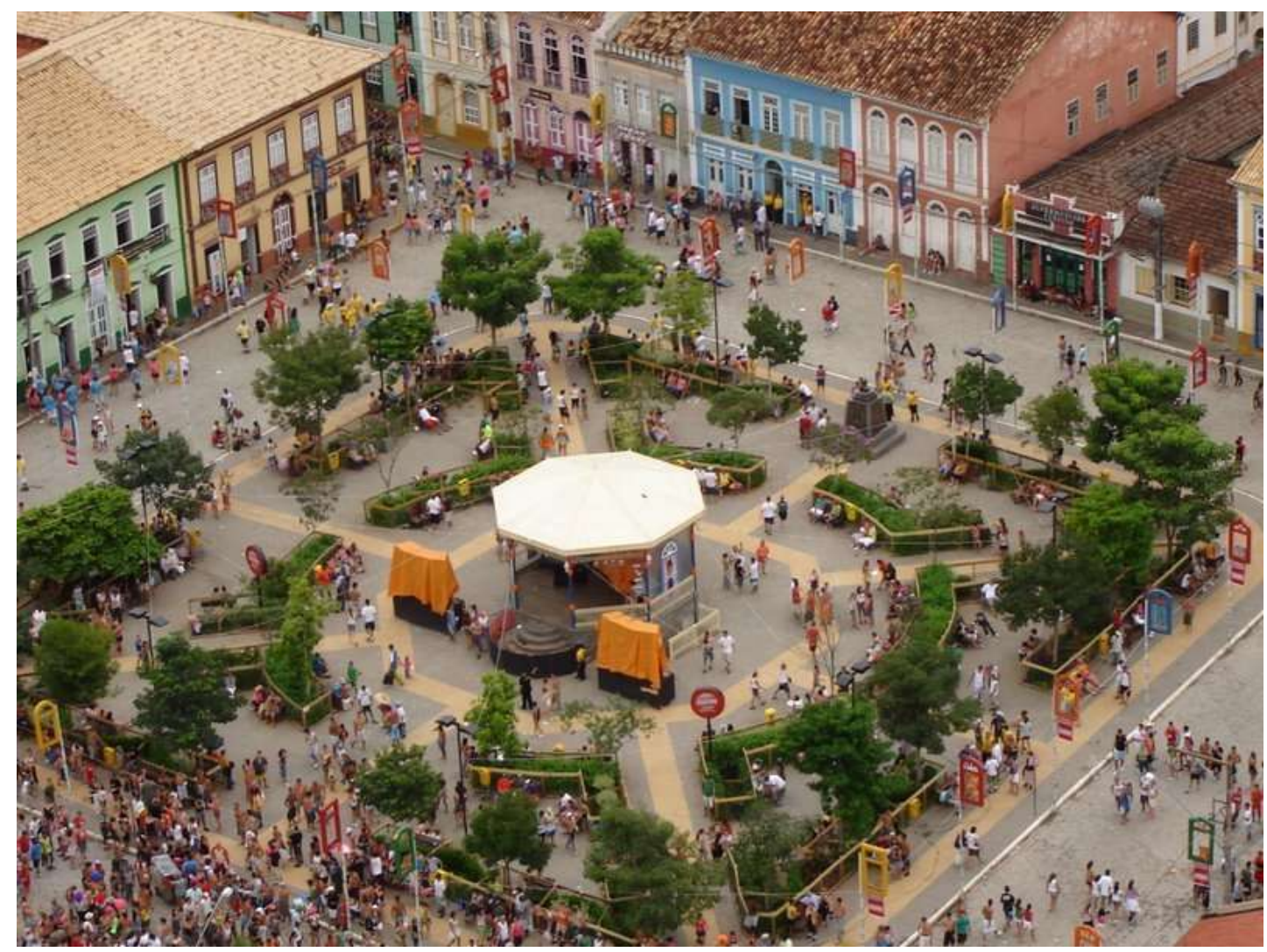

Fonte: PMSLP. 
Quanto a essa praça em São Luiz do Paraitinga, vale destacar que as cidades tradicionais de origem portuguesa apresentam grande diversidade de espaços públicos abertos que podem ser designados como praças. Estas podem ter diferentes funções e origem, distintas localidades na malha urbana, por estarem associadas a diferentes edifícios com dimensões diversas, sua forma pode ser regular ou irregular. Seja qual for a sua origem, as praças desempenham sempre um papel importante na estruturação da cidade.

A partir do século $\mathrm{XV}$ as praças passam a desempenhar um papel fundamental, estas ganharam destaque na estrutura funcional da cidade. As praças se tornaram os locais mais nobres desses núcleos, passando a se localizar ali as funções e as edificações mais importantes, sendo o espaço para o exercício da vida urbana, lugar de ver e ser visto, o espaço do vivido. A praça vai tornando-se cada vez mais regular, mais inserida na lógica formal dos planos geométricos, e vai assumir um papel cada vez mais importante na estruturação da cidade, atingindo seu apogeu no lluminismo setecentista, quando essa passa a assumir a função de geradora da malha urbana.

Segundo Teixeira (2006), ao longo da história urbana brasileira, a praça vai adquirindo uma importância cada vez maior e isso se dá pela crescente busca pela regularização dos traçados, expressão da proeminência da racionalidade da cultura urbana europeia e brasileira.

Em São Luiz do Paraitinga a praça exerce um papel importante na estruturação do espaço urbano devido a sua importância funcional e simbólica. É o lugar de encontro, da troca, de convivência e da sociabilidade da comunidade, condensando ali funções políticas, econômicas e sociais, funções essas que historicamente desempenhou e que conduziu a estruturação da cidade, o lugar por excelência onde o espaço concebido foi apropriado como espaço vivido.

Teixeira (2006) salienta que, em muitos casos, a exploração das relações entre o traçado urbano e a arquitetura deu origem à abertura de praças associadas a edificações singulares, como é o caso em São Luiz do Paraitinga. Para o IPHAN (2010), em nenhuma das praças das antigas cidades paulistas restou um conjunto tão significativo de sobrados, ressaltando a homogeneidade e a importância desse 
conjunto geminado composto por sobrados em arquitetura neoclássica que nos reportam a um período entre 1858 e 1870.

No século XVIII, praças como essa, quadradas ou retangulares, centradas na malha urbana e tendo um claro papel de elemento gerador do traçado tornam-se o modelo dominante, sendo pensadas como o centro da cidade, em termos simbólicos, funcionais e formais.

Nesta praça, deveriam estar localizados o pelourinho, a Igreja e a Casa de Câmara e Cadeia. Todas as casas deveriam ter suas fachadas construídas de acordo com a mesma tipologia, associando à praça o caráter de "formosura" (TEIXEIRA, 2006). Sendo assim, a Praça da Matriz em São Luiz mostra-se como um verdadeiro remanescente da tradição setecentista de organização desse elemento urbano, visto que todos os elementos citados pelo autor são observáveis nessa localidade.

Nesse sentido, o traçado urbano regular e seu elemento gerador, as praças, constituem-se um patrimônio fundamental das cidades, sendo que em São Luiz do Paraitinga essa relação ocorre de maneira clara e segura, o que pode ser comprovado pela função articuladora que desempenha em relação ao traçado urbano como um todo. As suas dimensões em relação ao núcleo urbano bicentenário, além da magnitude das edificações que a emolduram, com destaque para a Igreja Matriz de São Luís de Tolosa, ruída na inundação de 2010, ressaltam a importância da normatização, por parte do Estado, a ordem distante, que concebeu esse espaço, a tipologia arquitetônica e volumétrica das edificações, inclusive na dimensão dos vãos, regras estas que remontam a um período anterior ao da fundação desse povoamento.

Toda essa normatização imposta pela ordem distante a esse conjunto urbano, quando da sua fundação, configura-se em um espaço concebido por excelência, que hoje é apropriada pela população local como espaço vivido. Prova desse fato é a ocorrência de festas como a do Divino, o momento em que o lavrador agradece a Deus as boas colheitas, as Festas Juninas em comemoração a Santo Antônio, São João e São Pedro, a Festa dos Santos Reis que comemora a visita dos Reis Magos ao Menino Jesus, dentre outras. Durante essas festas são realizadas danças como a Dança de Fitas e a Catira, além da realização dos folguedos, onde 
se destacam a Cavalhada, a Congada, o Jongo e o Moçambique. Todas essas manifestações, segundo Pellegrine Filho (2008), têm origens remotas, são formas vivas e dinâmicas que se apresentam e se renovam em suas funções e significados, são eventos que marcam as comunidades de seus praticantes, são instrumentos valiosos de salvaguardar a memória desses grupos. Sem falar de um dos principais sustentáculos de identidade coletiva, as ligadas ao paladar, pois em poucos lugares em São Paulo é possível saborear um afogado, um arroz com pato ou suã de porco, um bolinho de farinha, uma canjiquinha com entrecosto, um pastel de angu ou uma paçoca de carne-seca. Todas essas comidas típicas podem ser saboreadas em um dos edifícios mais simbólicos da cidade, o Mercado Municipal. É a presença dessas manifestações culturais que confere ao patrimônio de São Luiz do Paraitinga uma genuína alma caipira, a relação entre o patrimônio material e o imaterial, e, segundo Francisco (2008), isso de dá não apenas pela sobrevivência dos bairros rurais e sua interação com a cidade, mas é o resultado da permanência de uma cultura citadina eminentemente caipira.

\section{FIGURA 5 - APRESENTAÇÃO DO MOÇAMBIQUE NA FESTA DO DIVINO EM 2009}

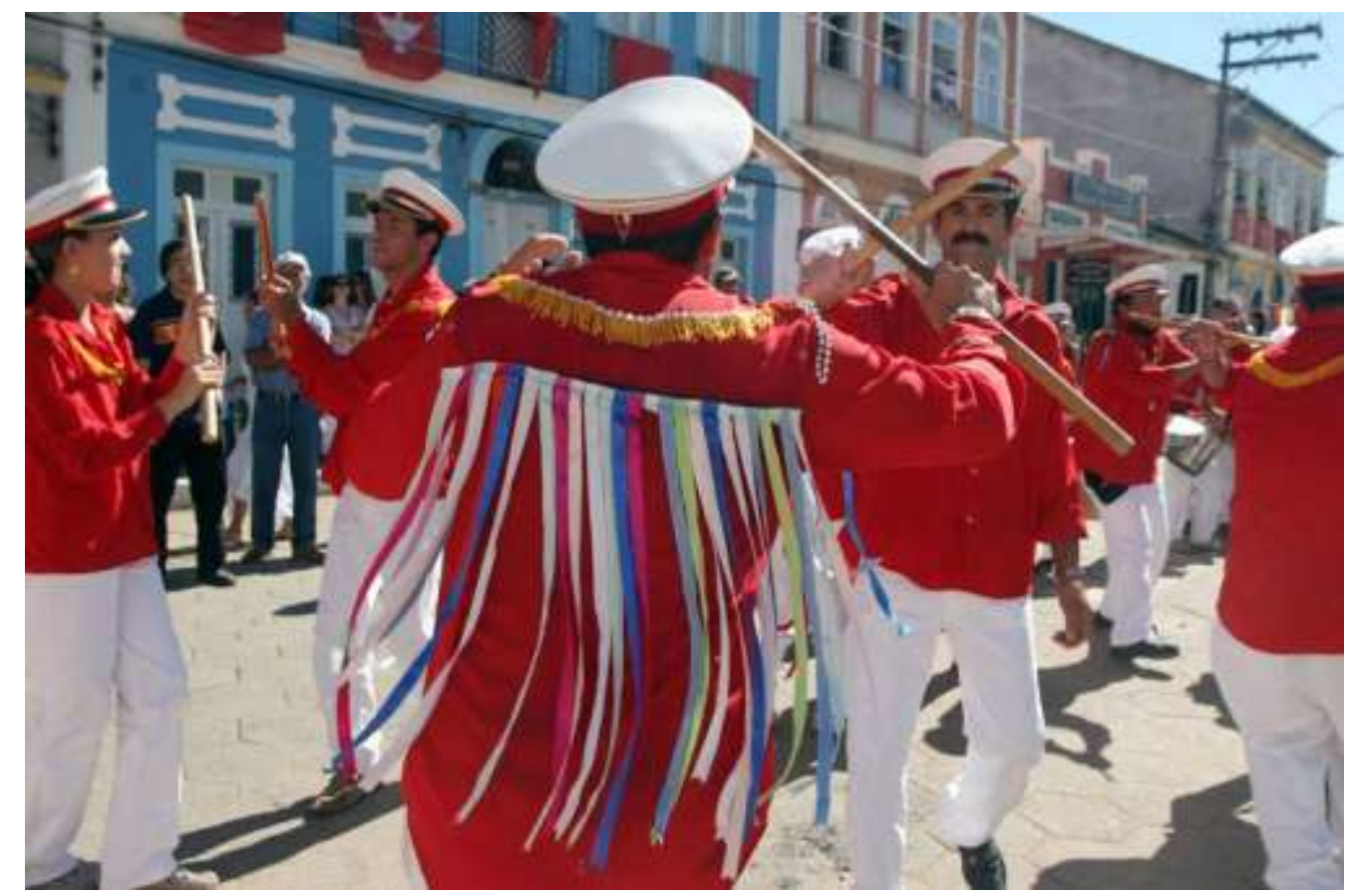

Foto: Kriz Knack. 
Contudo, não se pode terminar uma apreciação sobre o patrimônio cultural de São Luiz do Paraitinga sem abordar a questão da grande inundação de janeiro de 2010, quando este foi palco do maior desastre em área protegida por seu valor cultural na história do Brasil, tendo seu centro histórico arrasado pela maior cheia já registrada do Rio Paraitinga. Segundo um relatório preliminar divulgado pelo CONDEPHAAT, logo após o evento, dos 426 bens tombados, 65 foram seriamente danificados e 16 totalmente arruinados. Dentre os destruídos estão os principais símbolos do município: a Igreja Matriz de São Luís de Tolosa, do século XIX; a singela Capela de Nossa Senhora das Mercês, do início do século XVIII; o sobrado do "Grupo Escolar", do século XIX; e um sobrado datado de 1858, que fazia parte de um dos mais importantes conjuntos de fachadas remanescentes do planejamento ilustrado. 
FIGURA 6 - DESABAMENTO DA IGREJA MATRIZ DE SÃO LUIZ DE TOLOSA, EM 2010

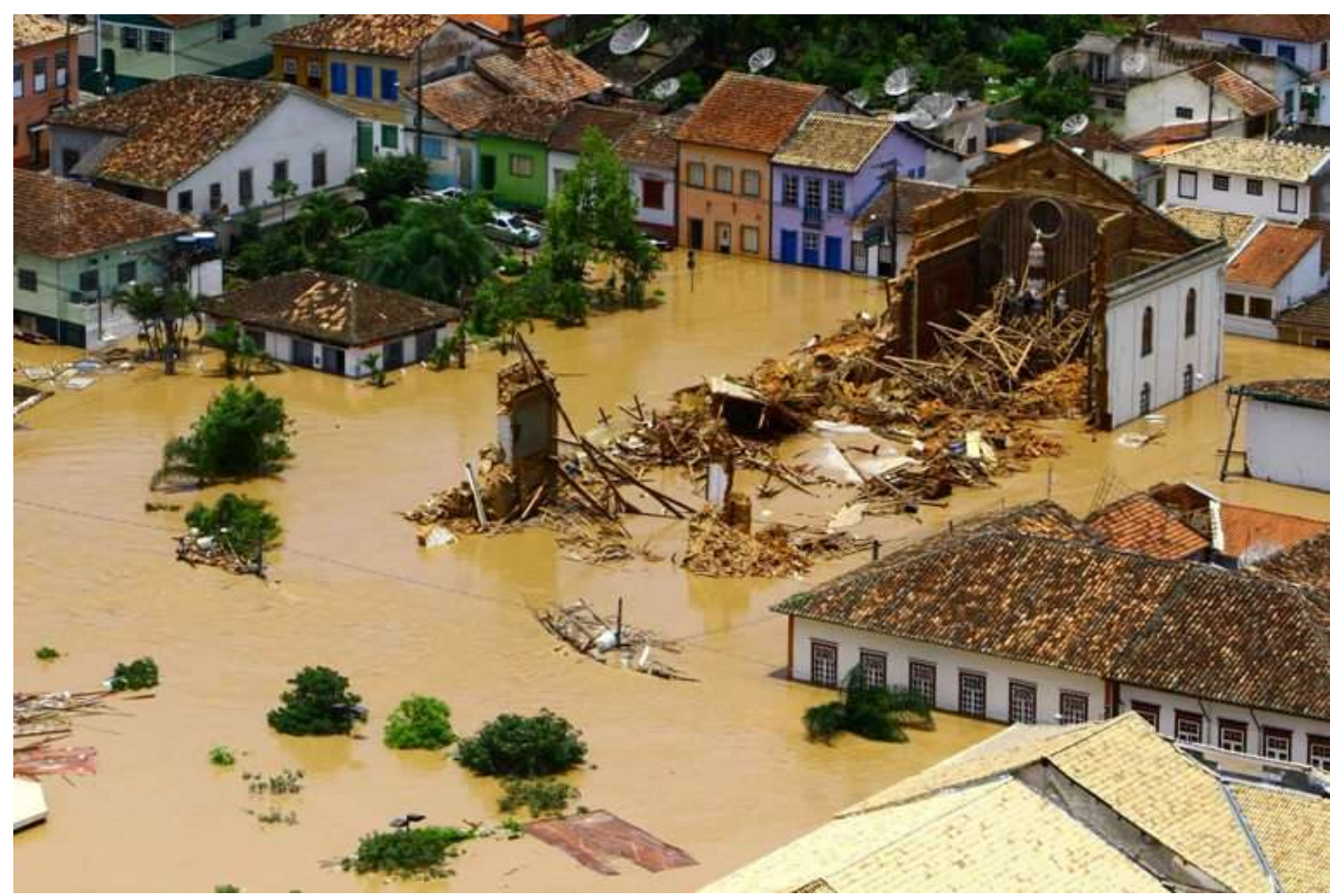

Fonte: Folha de São Paulo.

\section{FIGURA 7 - POPULAÇÃO SALVANDO AS IMAGENS SACRAS DOS ESCOMBROS} DA IGREJA MATRIZ DE SÃO LUIZ DE TOLOSA, EM 2010

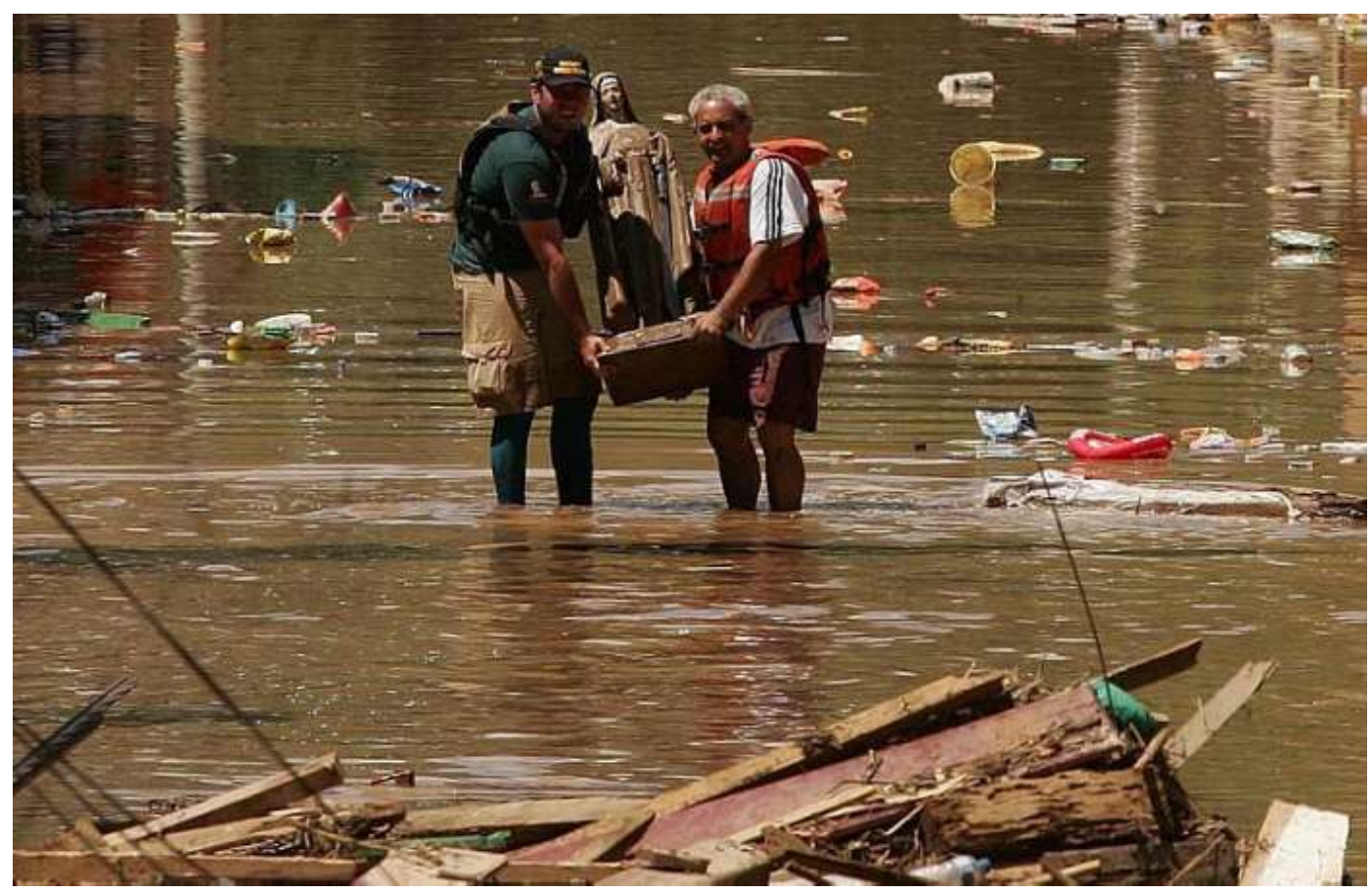

Fonte: Folha de São Paulo. 
MAPA 1 - IMÓVEIS TOMBADOS ATINGIDOS PELA INUNDAÇÃO DE 2010

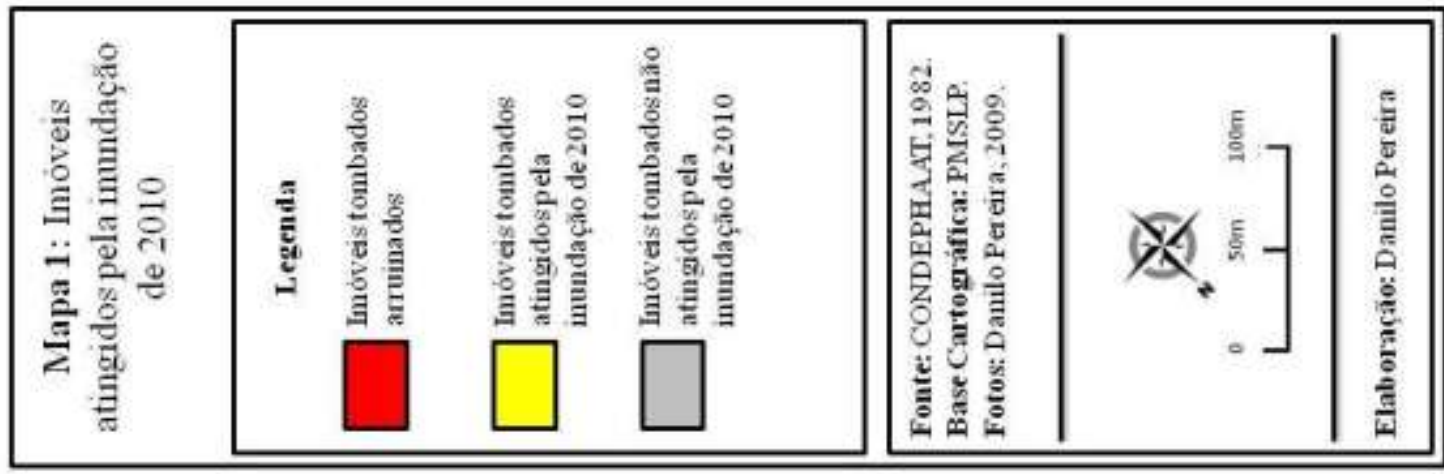

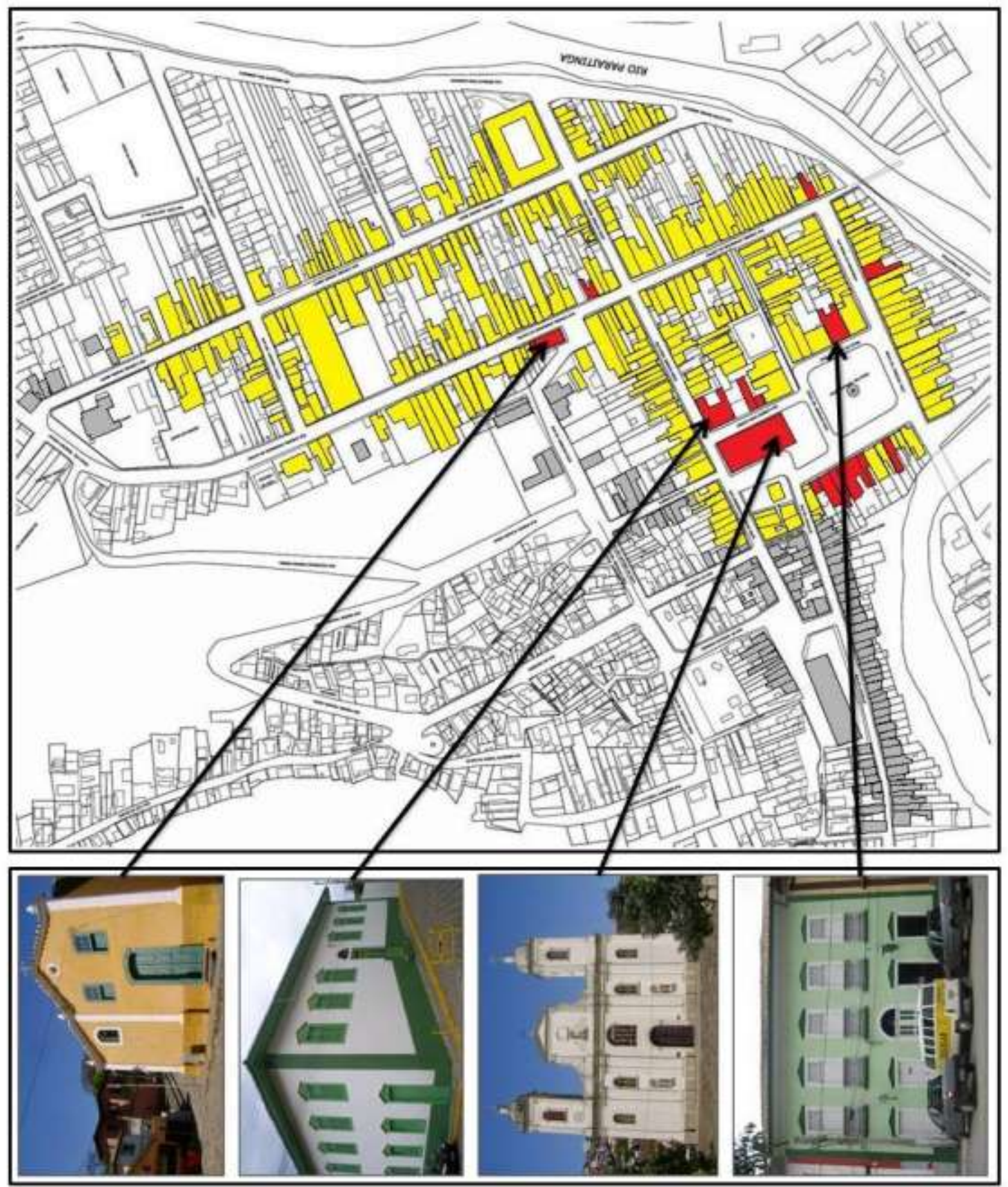

Fonte: CONDEPHAAT. 
Nesse momento de crise, o centro histórico de São Luiz do Paraitinga, que já se encontrava em processo de estudo para a sua proteção federal desde 2007, é tombado pelo IPHAN e obras de recuperação e salvamento são iniciados por esse instituto. Cabe ressaltar que estudos acerca da relevância paisagística e urbana de São Luiz do Paraitinga por esse órgão remontam aos anos de 1950, o que resultou no tombamento federal da casa onde nasceu o sanitarista Dr. Oswaldo Cruz em 1956 e no próprio centro histórico pelo CONDEPHAAT em 1982, este último levado ao conselho em conjunto com os técnicos do IPHAN à época.

É importante lembrar que enchentes ocorrem periodicamente em São Luiz do Paraitinga, visto que esse conjunto urbano localiza-se em uma área de várzea. Documentação antiga aponta outras duas grandes enchentes no município em 1864 e em 1882.

Segundo Pereira (2011), as perdas decorrentes dessa última inundação não podem ser encaradas apenas como perdas materiais, mas também como perdas da memória de uma comunidade, visto que, entre os bens arruinados estão os principais sustentáculos da identidade luizense. A Igreja Matriz foi o palco dos acontecimentos mais marcantes na vida daquelas pessoas, além de ser o principal local de reunião nas missas de domingo dessa comunidade fortemente católica, é o local onde essas pessoas foram batizadas, onde se casaram e batizaram seus filhos. Além disso, era onde se realizavam as cerimônias de entrega dos diplomas de conclusão do ensino médio e fundamental, ou seja, os principais acontecimentos da vida pessoal de cada luizense ocorreram dentro daquele edifício. Podemos dizer então que o seu desabamento acarretou a perda do principal sustentáculo de memória coletiva dessa comunidade. Se até o momento do desmoronamento da matriz a inundação promovia perdas individuais, após a sua queda passamos a ter uma grande perda coletiva. $\mathrm{E}$ esse fato torna-se ainda mais claro quando observamos como essa comunidade agiu quando as águas começaram a baixar, em vez de irem socorrer seus pertences pessoais, passam a recolher nos escombros das igrejas todos os objetos que para eles poderiam ser salvos, mesmo antes da chegada dos técnicos especializados dos órgãos de patrimônio. 
Além dessas perdas coletivas, temos que contar as perdas pessoais, de cada objeto, fotografia ou documento que carregava a história de cada um, além da história de toda a sua família, o que para Bosi (2003) são os objetos biográficos, que além de uma sensação estética ou de utilidade, são responsáveis por dar um "assentimento posição" das pessoas no mundo, à sua identidade. Ademais, os objetos que sempre estiveram presentes falam à alma em uma língua natal, são objetos que envelhecem com o seu proprietário e se incorporam à sua vida, representando uma experiência vivida, uma aventura efetiva do proprietário.

Para Marins (2008), o patrimônio cultural torna-se relevante na medida em que é interpretado como vetor da formação do indivíduo e das relações sociais, que dele se apropriam, reelaborando-os a si próprios. O patrimônio cultural de São Luiz do Paraitinga, indiscutivelmente, repercute sobre a formação dos indivíduos locais e das relações sociais, ou seja, sobre o peculiar patrimônio imaterial dos luizenses, visto que, como já discutimos anteriormente, esse lugar se configura como espaço vivido por excelência. Nesse sentido, torna-se imprescindível para a salvaguarda desse patrimônio intangível a recomposição desse patrimônio urbano brasileiro.

\section{CONSIDERAÇÕES FINAIS}

Após o tombamento, cabe aos órgãos de proteção zelar pelos bens listados, promovendo a manutenção e a valorização desses bens, além de difundir ações voltadas à educação da população no que concerne às questões que envolvem a preservação desse patrimônio.

Em São Luiz do Paraitinga, nunca houve por parte do CONDEPHAAT ações de educação patrimonial e, no que se refere à manutenção e valorização, as ações sempre foram insuficientes. O tombamento realizado por esse órgão se mostrou incapaz de implantar as diretrizes e normas que estabeleceu no processo de tombamento, mantendo um grande distanciamento com a população local, o que gerou um grande vazio institucional, vazio este que agora passa a ser ocupado pelo IPHAN, que tem se mostrado mais suscetível a dialogar com os verdadeiros agentes da preservação do patrimônio cultural, a população local. 
Assim, podemos afirmar que apenas dois fatores foram responsáveis pela manutenção desses bens no presente espaço geográfico: em um primeiro momento, a impossibilidade econômica em substituir esses imóveis por novos; e em um segundo, a relação de identidade que essa população possui com esses bens, prova disso era o grau de conservação que estes apresentavam até o advento da inundação. Segundo levantamento do IPHAN em 2009, dos 450 bens que compõem o centro histórico, apenas 4,5\% encontravam-se em estado de conservação ruim, $12 \%$ regular e $83,5 \%$ em bom estado de conservação, o que corrobora com o fato de que, mesmo com a ineficiência das políticas estaduais de preservação e sem uma orientação técnica devida, a população zelava pelo que ela tinha como seu patrimônio.

\section{BIBLIOGRAFIA}

BOCCHINI, B. São Paulo pode ter perdido maior conjunto de edificações do século XIX. In: Agência Brasil - Empresa Brasil de Comunicação. Disponível em:< http://agenciabrasil.ebc.com.br/noticia/2010-01-11/sao-paulo-pode-ter-perdido-maiorconjunto-de-edificacoes-do-seculo-19>. Acesso em: 11 jan. 2010.

BOSI, E. O tempo vivo da memória: ensaios de psicologia social. São Paulo: Ateliê Editorial, 2003.

BRASIL. Constituição da Republica dos Estados Unidos do Brasil (1934). Diário Oficial da União. Brasília, DF, jul. 1934.

. Constituição da República Federativa do Brasil (1988). Diário Oficial da União. Brasília, DF, out. 1998.

Decreto-Lei ${ }^{\circ} 25$ de 30 de novembro de 1937. Organiza a proteção ao patrimônio histórico e artístico nacional. Diário Oficial da União. Brasília, DF, Nov. 1837.

CARLOS, A.F.A. O Lugar no/do mundo. São Paulo: HUCITEC, 1996.

CHOAY, F. A Alegoria do Patrimônio. São Paulo: Ed. Unesp, 2000.

CORREIA, J.E.H. Vila Real de Santo António levantada em cinco meses pelo Marquês de Pombal. In: SANTOS, M. H. C. (Org.) Pombal Revisitado. Lisboa: Ed. Estampa, 1984, v. 2, p. 85-91. 
Vila Real de Santo António, um exemplo de urbanismo iluminista. In: CORREA, A. B. (Org.) Urbanismo e história urbana em El Mundo Hispano: Segundo Simposio. Madrid: Universidad Complutense de Madrid, v. 2, 1985.

FONSECA, M.C.L. O patrimônio em processo: Trajetória da política federal de preservação no Brasil. Rio de Janeiro: UFRJ/IPHAN, 1997.

FRANCISCO, L.R. de. A gente paulista e a vida caipira. In: SETUBAL, M.A.. Terra Paulista: histórias, arte e costumes. São Paulo: Imprensa Oficial, 2008. v. 3, p. 23-50.

IPHAN. Cartas Patrimoniais. Rio de Janeiro: IPHAN/MinC, 2004.

Dossiê de Tombamento - São Luiz do Paraitinga/SP: um programa da "ilustração". Proposta de tombamento da cidade configurada a partir do plano traçado no século XVIII. São Paulo: Minc/IPHAN, 2010.

LEFEBVRE, H.. A natureza e o domínio da natureza. In: LEFEBVRE, H. Introdução à Modernidade. Rio de Janeiro: Paz e Terra, 1969.

La production de l'espace. Paris: Anthropos, 1974.

O direito a cidade. São Paulo: Moraes, 1991.

A revolução urbana. Belo Horizonte: UFMG, 2004.

LUZ, R.R. São Luiz do Paraitinga: o último reduto caipira. São Paulo: BH Gráfica e Editora, 2004.

MARINS, P.C.G. Trajetória de preservação do patrimônio cultural paulista In: SETUBAL, M. A. Terra Paulista: histórias, arte e costumes. São Paulo: Imprensa Oficial, 2008. v. 4, p.137-168.

PEREIRA, D.C. Gestão Patrimonial no Brasil: o caso de São Luiz do Paraitinga. In: Revista Geográfica de América Central, San José, v.2, n. 47E, p. 1-16, 2011.

PEREIRA, D.C. O Patrimônio ambiental urbano de São Luiz do Paraitinga e as políticas públicas de preservação. Monografia (Trabalho de Graduação Individual em Geografia - Faculdade de Filosofia, Letras e Ciências Humanas - USP) Universidade de São Paulo, São Paulo, 2012.

SANTOS, M. Por uma economia política da cidade: o caso de São Paulo. São Paulo: Hucitec, 1994.

. Espaço e método. São Paulo: Nobel, 1997. 
A natureza do espaço: técnica e tempo, razão e emoção. São Paulo: Edusp, 2002.

SANTOS, M. e SILVEIRA, M.L. O Brasil: território e sociedade no início do século XXI. Rio de Janeiro: Record, 2001, 473p.

SECRETARIA DA CULTURA DO ESTADO DE SÃO PAULO. Resolução $n^{\circ} 55$ de outubro de 1982. Dispõe sobre o Tombamento de São Luiz do Paraitinga. Diário Oficial. São Paulo, SP, 1982

SCIFONI, S. A construção do patrimônio natural. Tese (Doutorado em Geografia - Faculdade de Filosofia, Letras e Ciências Humanas - USP) Universidade de São Paulo, São Paulo, 2006.

Os diferentes significados do patrimônio natural. Revista Diálogos, DHI/UEM, vol. 10, n. 3, p. 55-78, 2006.

Por uma geografia política dos recursos naturais. In: PAES, Maria Teresa Duarte e OLIVEIRA, Melissa Ramos da Silva (orgs). Geografia, Turismo e Patrimônio Cultural. São Paulo: FAPESP, 2009, p. 179-206.

SCIFONI, S. e RIBEIRO, W.C. Preservar: por que e para quem? In: Revista Patrimônio e Memória. Assis: UNESP, v. 2, p. 1-12, 2006.

SETUBAL, M.A.. Terra Paulista: histórias, arte e costumes. São Paulo: Imprensa Oficial, 2008.

SILVA, V. A. Paulistas em movimento: bandeiras, monções e tropas. In: SETUBAL, M.A.. Terra Paulista: histórias, arte e costumes. São Paulo: Imprensa Oficial, 2008. v. 1, p. 55-101.

TEIXEIRA, M.C. O urbanismo português, Séculos XIII-XVIII Portugal-Brasil. Lisboa: Livros Horizonte, 1999.

A Praça nas morfologias urbanas brasileiras. In: Simpósio de Arquitetura da Cidade nas Américas: Diálogos Contemporâneos entre o local e o global. Sevilha, 2006.

(Recebido em: 16/05/2012. Aceito em 08/10/2012). 